\title{
Effect of temperature on hypoxia tolerance and its underlying biochemical mechanism in two juvenile cyprinids exhibiting distinct hypoxia sensitivities
}

\section{Wei He, Zhen-Dong Cao, Shi-Jian Fu*}

Laboratory of Evolutionary Physiology and Behavior, Chongqing Key Laboratory of Animal Biology, Chongqing Normal University, Chongqing, 401331, China

Running title: Temperature and hypoxia tolerance

*Corresponding Author

E-mail: shijianfu9@hotmail.com

\begin{abstract}
It is increasingly important to investigate the effect of temperature on hypoxia tolerance in fish species, as worldwide hypoxia worsens with increases in global warming. We selected the hypoxia-tolerant crucian carp (Carassius carassius) and the hypoxia-sensitive Chinese bream (Parabramis pekinensis) as model fish and investigated their hypoxia tolerance based on the critical oxygen tension of the routine metabolic rate $\left(\dot{M} \mathrm{O}_{2 \text { rout }}\right)\left(P_{\text {crit }}\right)$, aquatic surface respiration $\left(\mathrm{ASR}_{\text {crit }}\right)$ and loss of equilibrium (LOE $\left.\mathrm{Lrit}\right)$ after two weeks of acclimation at either 10, 20 or $30{ }^{\circ} \mathrm{C}$. We also measured the tissue substrate (glycogen and glucose of muscle and liver) and lactate levels of both normoxia- and hypoxia-treated fish (post-LOE). Crucian carp exhibited significantly lower $P_{\text {crit }}$ and $\mathrm{LOE}_{\text {crit }}$ but not $\mathrm{ASR}_{\text {crit }}$, which suggested that ASR is not a reliable differentiator of fish species that exhibit distinct ecological characteristics. Crucian carp possessed higher hypoxia tolerance, partially due to a higher tissue glycogen reserve, which provides cellular fuel under severe hypoxia, as well as higher lactate tolerance and clearance ability than Chinese bream. The hypoxia tolerance was maintained in crucian carp but was decreased in Chinese bream as the temperature increased. The difference between the two species is based on the greater recruitment of tissue glycogen, resulting in an increased level of
\end{abstract}


glucose, the cellular fuel that provides energy via anaerobic pathways during hypoxia in crucian carp than in Chinese bream. In addition, crucian carp possessed the greater liver lactate clearance capacity, which avoids lactate self-poisoning, and the smaller increase in the $\dot{M}_{2 \text { rout }}$, thereby reducing the oxygen demand at higher temperatures compared to Chinese bream. Furthermore, substrate shortage and decreased lactate tolerance at high temperatures in Chinese bream might also contribute to the difference in hypoxia tolerance between the two species.

Keywords: cyprinid, glycogen, hypoxia tolerance, lactate, $\dot{M}_{2 \text { rout }}$, temperature

\section{Introduction}

Environmental hypoxia is a common abiotic challenge caused by temperature fluctuations, low photosynthetic activity and low or stagnant water flow that many aquatic organisms experience in their habitat (Karim et al., 2003; Diaz and Breitburg, 2009; Martínez et al., 2011). At any sufficiently low level of dissolved oxygen would negatively impact the behavior and/or physiology of fish. In general, fish respond to hypoxia via a set of physiological, behavioral, biochemical and molecular responses that serve to either enhance oxygen uptake in the oxygen-depleted environment or limit the potentially devastating consequences of oxygen limitation in the tissue. First, fish may downregulate metabolism to decrease the oxygen demand during hypoxia exposure. The critical oxygen tension $\left(P_{\text {crit }}\right)$ for routine oxygen consumption rate $\left(\dot{M}_{2 \text { rout }}\right)$ is the minimum oxygen level required to sustain the routine oxygen consumption rate. $P_{\text {crit }}$ is thought to reflect the ability of an organism to extract oxygen from the environment to maintain $\dot{M O}_{2 \text { rout }}$ as oxygen tension decreases; a lower $P_{\text {crit }}$ is associated with higher hypoxia tolerance. Consequently, $P_{\text {crit }}$ has been employed routinely as an important measure of hypoxia tolerance in aquatic organisms, including fish species (Pörtner and Grieshaber, 1993; Chapman et al., 2002; Nilsson and Östlund - Nilsson, 2008; Mandic et al., 2009). In addition to the downregulation of metabolism, aquatic surface respiration (ASR) is one of the most common responses to hypoxia (Graham, 1990; Diaz and Rosenberg, 1995; Soares et al., 2006; Urbina et al., 2011), whereby fish breathe water from surface film, which allows them to access the more highly oxygenated water at the water-air interface (Shingles et 
al., 2005; Sloman et al., 2006). ASR is hypothesized to be triggered by environmental oxygen tensions at which respiratory mechanisms fail to compensate for environmental hypoxia (Takasusuki et al., 1998). If the oxygen tension decreases further, fish may exhibit loss of equilibrium (LOE). The oxygen tension threshold for $\mathrm{LOE}\left(\mathrm{LOE}_{\text {crit }}\right)$, which represents the oxygen tension at which the fish can no longer maintain body balance due to systemic disorganization, is considered as an ecological index of lethality (Coutant, 1969; Paladino et al., 1980; Chapman et al., 1995; Currie et al., 2004). Therefore, $P_{\text {crit }}$, the critical oxygen tension for ASR (ASR crit), and $\mathrm{LOE}_{\text {crit }}$ are three potentially useful hypoxia tolerance indicators for fish (Chapman et al., 2002; Barnes et al., 2011; Mandic et al., 2013).

In recent years, hypoxia in aquatic environments worldwide has been further aggravated due to the effects of anthropogenic global warming (Diaz and Rosenberg, 2008; Roze et al., 2013) because temperature plays a fundamental role in regulating metabolic processes and the elevation of temperature increases the respiration rates of organisms while diminishing oxygen solubility (Guderley, 2004; Sørensen et al., 2014). As a result, the combination of increased temperature and reduced oxygen availability is currently impacting upon several freshwater and marine fish populations (Ficke et al., 2007; Rabalais et al., 2009). Therefore, it has become increasingly important to investigate the effect of temperature on hypoxia tolerance in fish species and to understand the mechanisms that fish use to persist and survive under hypoxic conditions at various temperatures. In general, it has been demonstrated that the $P_{\text {crit }}$ is significantly increased, indicating reduced hypoxia tolerance, as temperature increases in fish species, such as barramundi (Lates calcarifer) and coral-dwelling gobies (Gobiodon histrio and G. erythrospilus) (Collins et al., 2013; Sørensen et al., 2014). However, few reported studies have attempted to elucidate the effect of temperature on the hypoxia tolerance of fish species using all three of the aforementioned parameters. Therefore, the first aim of this study was to investigate the effect of temperature on hypoxia tolerance in fish species based on $P_{\text {crit }}, \mathrm{ASR}_{\text {crit }}$ and $\mathrm{LOE}_{\text {crit }}$ to reveal the connections between the physiology and the behavior of experimental fish by analyzing and comparing these parameters. To perform our investigation, we selected two eurythermic cyprinids with closely phylogenetical relationship from the Three Gorges Reservoir, China, i.e. crucian carp (Carassius carassius), a hypoxia-tolerant cyprinid, and Chinese bream (Parabramis pekinensis), a hypoxia-sensitive cyprinid according to a recently 
published study (Dhillon et al., 2013; Fu et al., 2014) as experimental models. The water temperature in this region increased in recent years after construction of Three Gorges Dam under the background of global warming. Thus, the sensitivities of hypoxia tolerance to temperature among different fish species might result in profound effect on their thriving in future in thermal changing environment.

Under hypoxic conditions, two biochemical strategies are widely used in fish species, i.e., decreasing energy turnover and increasing the energetic efficiency of ATP-producing pathways, including suppressing aerobic metabolic ATP production, enhancing glycolytic capacity and alternative pathways that display improved energetic efficiency (Seibel, 2010). These changes are associated with the mobilization, transportation and utilization of substrates (primarily glycogen and glucose from liver and muscle) and the transportation and clearance of metabolites (primarily lactate) (Mandic et al., 2013). However, the extent and location of the metabolites used depend on the duration and severity of hypoxia, as well as the pathway, tissue and species involved (Martínez et al., 2011). Crucian carp is considered as the champion of hypoxia tolerance (Nilsson and Renshaw, 2004; Dhillon et al., 2013). Its impressive hypoxia tolerance is associated with its large muscle and liver glycogen stores and its high lactate tolerance (Lutz and Nilsson, 1997; Nilsson and Renshaw, 2004). However, compared to crucian carp, Chinese bream (Parabramis pekinensis) is much more sensitive to hypoxia (Fu et al., 2014). Furthermore, the adaptive responses of crucian carp to hypoxia, such as morphological changes in the gills that reduce the water-blood diffusion distance (Sollid et al., 2003) during hypoxia (or high temperature) and the ability to convert lactate to ethanol and $\mathrm{CO}_{2}$ to avoid self-lactate poisoning (Van Waarde, 1991), are absent from Chinese bream (Fu et al., 2014). The biochemical responses to hypoxia at different temperatures may also differ between these two fish species. Thus, the second aim of this study was to investigate the underlying biochemical mechanism of the potentially different hypoxia tolerance responses at varying temperatures between the two fish species.

In order to investigate the difference of the hypoxia tolerance and its underlying biochemical mechanism with the increase of temperature between the two cyprinids, we selected the temperature range $\left(10\right.$ to $30^{\circ} \mathrm{C}$ ) based on the annual variation of local water bodies in Chongqing, China. Then, we measured the decrease in oxygen tension based on the $\dot{M}_{2 \text { rout }}$, 
ASR and LOE of fish after two weeks of acclimation at 10,20 or $30^{\circ} \mathrm{C}$. We also measured the tissue substrate levels and the lactate content immediately after LOE in each thermal acclimation group.

\section{Material and Methods}

\subsection{Fish}

All juvenile crucian carp (Carassius carassius) and Chinese bream (Parabramis pekinensis) were obtained from a local farmer. The fish were transported to Chongqing Normal University and maintained in an indoor re-circulating rearing system for one week. During this period, the temperature of the dechlorinated fresh water was maintained at $20 \pm 2{ }^{\circ} \mathrm{C}$. The photoperiod was 12L:12D, and the oxygen concentration was maintained above $7 \mathrm{mg} \mathrm{L}^{-1}$. One tenth of the water was replaced daily. Throughout the experimental period, the fish were fed daily (10:00 AM) to satiation using commercial food. All of the experiments were performed according to the Guidelines on the Humane Treatment of Laboratory Animals established by the Ministry of Science and Technology of the People's Republic of China.

\subsection{Temperature acclimation}

After one week of holding, 72 healthy fish from each species were randomly selected and assigned to three temperature $\left(10,20\right.$ and $\left.30^{\circ} \mathrm{C}\right)$ treatment groups (24 for each group). The average body mass of the crucian carp and the Chinese bream were $7.32 \pm 0.20$ and $5.90 \pm 0.25$ $\mathrm{g}$, respectively. The water temperature was gradually increased or decreased to the target temperature by two-centigrade steps each day. Then, the experimental fish were housed at the target temperature for another two weeks before any measurements. The rearing conditions in the tanks were identical to those of the acclimation period.

\subsection{Measurement of hypoxia indicators}

\subsubsection{Determination of $\dot{M O}_{2}$ and $\underline{P}_{\text {crit }}$}

$\dot{M} \mathrm{O}_{2}$ and $P_{\text {crit }}$ for each fish (eight in each group) were determined using closed respirometry (Zhang et al., 2010). Each fish was placed in the respirometer chamber overnight ( $8-12 \mathrm{~h}$ ) to habituate to the apparatus and reduce the effect of handling stress. During this time, the respirometer was submerged in a thermal-controlled water bath (target temperature $\pm 0.5^{\circ} \mathrm{C}$ ). Each respirometer chamber remained open, allowing air-saturated water to flow into the respirometer using an attached circulating water pump. Then, the respirometer was sealed, and 
the decrease in oxygen concentration was continuously recorded every 2 min using an oxygen probe (HQ30, Hach Company, Loveland, Colorado, USA). The measurements were stopped when the oxygen concentration displayed no further decrease. Then, the fish was removed from the chamber to measure its body mass.

The following formula was used to calculate the $\dot{M} \mathrm{O}_{2}\left(\mathrm{mg} \mathrm{kg}^{-1} \mathrm{~h}^{-1}\right)$ of each fish:

$\dot{M} \mathrm{O}_{2}=\left(\left[\mathrm{O}_{2}\right]_{\mathrm{k}}-\left[\mathrm{O}_{2}\right]_{\mathrm{k}+1}\right) \mathrm{V} /(\mathrm{t} \times \mathrm{m})$

where $\left[\mathrm{O}_{2}\right]_{\mathrm{k}}$ refers to the oxygen concentration $\left(\mathrm{mg} \mathrm{L}^{-1}\right)$ at the sampling time point $\mathrm{k},\left[\mathrm{O}_{2}\right]_{\mathrm{k}+1}$ represents the concentration at the following time point (these values were calculated according to the $\mathrm{O}_{2}$ solubility coefficient in water at the corresponding temperature and pressure), $\mathrm{V}(\mathrm{L})$ represents the total volume of the respirometer minus the volume of the fish, $t(h)$ corresponds to the interval between the time points $\mathrm{k}$ and $\mathrm{k}+1$, and $\mathrm{m}(\mathrm{kg})$ represents the body mass of the fish.

$P_{\text {crit }}$, the point at which $\dot{M} \mathrm{O}_{2}$ could no longer be maintained by a further reduction in the water oxygen tension, was estimated for each fish using the two-segment linear model described by Yeager and Ultsch (Yeager and Ultsch, 1989). The $\dot{M} \mathrm{O}_{2 \text { rout }}$ was considered as the mean value of all $\dot{M} \mathrm{O}_{2}$ measured at oxygen tensions greater than $P_{\text {crit }}\left(\right.$ Chen et al., 2010). Then, the unit of $P_{\text {crit }}$ was calculated according to the $\mathrm{O}_{2}$ solubility coefficient in water at the corresponding temperature and pressure and converted from $\mathrm{mg} \mathrm{L}^{-1}$ to torr.

The thermal sensitivity of the $\dot{M}_{2 \text { rout }}$ and $P_{\text {crit }}$ (i.e., $Q_{10}$ ) was calculated using the following formula:

$Q_{10}=\left(\mathrm{R}_{2} / \mathrm{R}_{1}\right)^{10 /(\mathrm{T} 2-\mathrm{T} 1)}$

where $\mathrm{R}_{1}$ and $\mathrm{R}_{2}$ represent the $\dot{M} \mathrm{O}_{2 \text { rout }}$ and the $P_{\text {crit }}$ at temperatures $\mathrm{T}_{1}$ and $\mathrm{T}_{2}$, respectively.

\subsubsection{ASR and LOE}

The oxygen tension at which individual fish exhibited ASR and LOE were measured during the same experiment. Briefly, each fish $(\mathrm{n}=8)$ was transferred to a $39 \mathrm{~L}$ (floor space $\times$ height $=$ $0.196 \mathrm{~m}^{2} \times 0.2 \mathrm{~m}$ ) tank that was maintained under flow-through conditions at each temperature for $2 \mathrm{~h}$ prior to the experiment. The water in this tank was circulated by a pump. At the start of the experiment, a plastic film was placed below the water line to prevent the fish from accessing the water-air interface. Then, the oxygen tension was manipulated via bubbling with nitrogen gas. The water temperature was maintained at the target temperature $\pm 0.2{ }^{\circ} \mathrm{C}$ using a thermo-regulated water bath. The oxygen tension was measured using an immersed oxygen probe (HQ30, Hach Company, Loveland, CO, USA). The oxygen tension was lowered from the normoxic level (approximately $95 \%$ saturation) to $2.5 \mathrm{mg} \mathrm{L}^{-1}$ over the course of $1 \mathrm{~h}$ by bubbling 
with nitrogen gas rapidly. After this point, the oxygen tension was decreased to $1.5 \mathrm{mg} \mathrm{L}^{-1}$ within 0.5 hour, then decreased by steps of $0.2 \mathrm{mg} \mathrm{L}^{-1}$ to a final oxygen tension of $0 \mathrm{mg} \mathrm{L}^{-1}$. The fish was maintained for $10 \mathrm{~min}$ at each oxygen tension level, and the change in the oxygen tension between the steps occurred in less than $3 \mathrm{~min}$. ASR of individual fish was defined as the point at which the fish rose to the surface and continued branchial respiration with its mouth near the air - water interface (Kramer, 1983; Chapman et al., 1995; Yang et al., 2013). The critical ASR ( $\mathrm{ASR}_{\text {crit }}$ ) was defined as the oxygen tension at which the fish performed the ASR event for the first time. The ASR events were monitored throughout the entire examination period. Briefly, at each oxygen tension, the total number of ASR events was counted over successive $5 \mathrm{~min}$ intervals (from $2.5 \mathrm{~min}$ to $7.5 \mathrm{~min}$ ). LOE of the fish was defined as the failure of the fish to maintain a dorsoventral orientation (Mandic et al., 2013). Because crucian carp exhibited no LOE behavior under this protocol, we recorded the duration that crucian carp performed the LOE behavior after exposure to anoxic conditions. ASR $\mathrm{Arit}_{\text {cit }}$ and $\mathrm{LOE}_{\text {crit }}$ were determined as follows (Dhillon et al., 2013):

$$
\begin{gathered}
\mathrm{ASR}_{\text {crit }}=\mathrm{PO}_{2}+(\mathrm{t} / \mathrm{T}) \Delta \mathrm{PO}_{2}, \\
\mathrm{LOE}_{\text {crit }}=\mathrm{PO}_{2}+(\mathrm{t} / \mathrm{T}) \Delta \mathrm{PO}_{2},
\end{gathered}
$$

in which $\mathrm{PO}_{2}$ represents the penultimate oxygen tension; $\Delta \mathrm{PO}_{2}$ corresponds to the decrease in the oxygen tension; $t$ represents the time required for the fish to lose equilibrium at the final $\mathrm{PO}_{2}$, and $\mathrm{T}$ corresponds to the duration maintained at each $\mathrm{PO}_{2}$.

The fish was removed from the experimental tank and placed in an overdose of neutralized tricaine methane-sulfonate (MS-222, $400 \mathrm{mg} \mathrm{L}^{-1}$ ) water immediately after the LOE test. Then, the arterial blood, the dorsal white muscle, the liver and the brain were sampled and immediately transferred to liquid nitrogen. Subsequently, these samples were frozen $\left(-80{ }^{\circ} \mathrm{C}\right)$ for later analysis.

\subsection{Biochemical measurements}

Eight fish were selected from each acclimated temperature group after $48 \mathrm{~h}$ of fasting and were euthanized immediately via an overdose of neutralized tricaine methane-sulfonate (MS-222, $400 \mathrm{mg} \mathrm{L}^{-1}$ ). Then, the arterial blood, the dorsal white muscle, the liver and the brain were sampled to measure the metabolite content. To investigate substrate utilization and metabolic waste production during hypoxia exposure, the same tissues were also sampled from fish immediately after the LOE test $(\mathrm{n}=8)$. The blood was transferred to a $1.5-\mathrm{mL}$ centrifuge tube and centrifuged at $4000 \mathrm{r}$ for $5 \mathrm{~min}$ at $4{ }^{\circ} \mathrm{C}$. The separated plasma and the samples of muscle, liver and brain tissue were frozen $\left(-80^{\circ} \mathrm{C}\right)$ for later analysis. The plasma, muscle, liver and 
brain lactate contents were measured using the p-phenylphenol method (Zhang et al., 1997). The glycogen and glucose contents in both the liver and the white muscle were measured using the anthrone method (Huang et al., 1995). The metabolite content was measured in triplicate using a 96-well microplate spectrophotometer (Spectra Max 190; Molecular Devices, USA) at $25 \pm 0.5^{\circ} \mathrm{C}$.

\subsection{Statistical analysis}

SPSS version 17.0 was used for the data analysis. The data are expressed as the mean values \pm S.E.M. The effect of species and temperature on the $\dot{M} \mathrm{O}_{2 \text { rout }}, P_{\text {crit }}$ and $\mathrm{ASR}_{\text {crit }}$ were analyzed via two-way analysis of variance (ANOVA). The effect of temperature on $\mathrm{LOE}_{\text {crit }}$ was analyzed via one-way ANOVA. The effect of species, temperature and oxygen tension on the total number of ASR was analyzed via three-way repeated measures ANOVA; the ANOVA was followed by two-way ANOVA to analyze the effect of temperature and oxygen tension within each species. The effect of species, temperature and hypoxia on the metabolite content of each tissue was analyzed via three-way ANOVA. ANOVA was followed by Duncan's test to identify significant differences in the means $(P<0.05)$.

\section{Results}

\subsection{Hypoxia tolerance}

\section{$\underline{3.1 .1 \dot{M}} \underline{2 r o u t}_{\text {and } P_{\text {crit }}}$}

The average body mass of crucian carp was significantly larger than that of Chinese bream $(P<$ 0.05) (Table 1). However, there was no significant difference between the temperature groups within each species. In both fish species, the $\dot{M}_{2 \text { rout }}$ remained constant over a broad range of water oxygen tension but declined at oxygen tensions below $P_{\text {crit }}$ at all acclimated temperatures, as was expected (Fig. 1).

The effect of species on the $\dot{M} \mathrm{O}_{2 \text { rout }}$ varied with respect to temperature (interaction effect, $P=$ 0.001). The $\dot{M} \mathrm{O}_{2 \text { rout }}$ of crucian carp was significantly higher than that of Chinese bream at $10^{\circ} \mathrm{C}$, while this difference was reversed at $30^{\circ} \mathrm{C}$. Temperature resulted in a significant effect on the $\dot{M} \mathrm{O}_{2 \text { rout }}(P<0.001)$. The $\dot{M} \mathrm{O}_{2 \text { rout }}$ of crucian carp increased significantly when the temperature was increased from 10 to $20{ }^{\circ} \mathrm{C}(P<0.05)$ (the $Q_{10}$ of $\dot{M} \mathrm{O}_{2 \text { rout }}$ was 1.78$)$; whereas the $\dot{M} \mathrm{O}_{2 \text { rout }}$ displayed no further increase when the temperature was increased from 20 to $30{ }^{\circ} \mathrm{C}$ (the $Q_{10}$ of $\dot{M} \mathrm{O}_{2 \text { rout }}$ was 0.99 ). However, the $\dot{M} \mathrm{O}_{2 \text { rout }}$ of Chinese bream increased with 
temperature, and there was a significant difference among the three temperature groups $(P<$ 0.05) (the $Q_{10}$ of $\dot{M} \mathrm{O}_{2 \text { rout }}$ were 2.61 and 1.28 , respectively as the temperature increased from 10 to $20{ }^{\circ} \mathrm{C}$ and 20 to $30{ }^{\circ} \mathrm{C}$ ). Species resulted in a significant effect on $P_{\text {crit. }}$. The $P_{\text {crit }}$ values of crucian carp were significantly lower than those of Chinese bream $(P=0.007)$. Temperature had no significant effect on $P_{\text {crit }}$ in either fish species. The $Q_{10}$ of $P_{\text {crit }}$ at 10 and $20{ }^{\circ} \mathrm{C}$ was 0.92 in both fish species, and that at 20 and $30{ }^{\circ} \mathrm{C}$ was 1.00 and 0.86 in crucian carp and Chinese bream, respectively.

\section{$\underline{3.1 .2 \mathrm{ASR}}$}

Temperature resulted in a significant effect on the ASR pattern, and this effect varied between the species ( $\mathrm{F}=4.686, P=0.010)$ (Fig. 2). In crucian carp, the fish performed ASR at all oxygen tensions, including normoxia; however, the number of ASR events increased as the oxygen tension decreased at all three temperatures. In Chinese bream, the fish exhibited no ASR behavior until $3.60 \pm 0.14,5.45 \pm 0.56$ and $9.13 \pm 0.54$ torr at 10,20 and $30^{\circ} \mathrm{C}$, respectively. After that, the fish performed more ASR events as the oxygen tension decreased. In general, the fish in the higher temperature group exhibited ASR at a higher oxygen tension, and the number of ASR events increased more profoundly as the oxygen tension decreased compared to those in the lower temperature group.

The $\mathrm{ASR}_{\text {crit }}$ of crucian carp was significant higher than those of Chinese bream for all three temperature groups $(\mathrm{F}=39.02, P<0.001)$ (Fig. 3). The $\mathrm{ASR}_{\text {crit }}$ displayed no variation among the three temperature groups in crucian carp, whereas the $\mathrm{ASR}_{\text {crit }}$ increased significantly as the temperature increased in Chinese bream.

\subsubsection{LOE}

Crucian carp exhibited no LOE behavior till the oxygen tension reached the $0 \mathrm{mg} \mathrm{L}^{-1}$ under the LOE protocol as adopted in Chinese bream. However, the crucian carp exhibited LOE after exposure to anoxia for $23.64 \pm 2.14,24.20 \pm 3.11$ and $25.49 \pm 4.63 \mathrm{~min}$ at $10,20,30{ }^{\circ} \mathrm{C}$, respectively, and there was no significant difference among the three temperature groups. The $\mathrm{LOE}_{\text {crit }}$ of Chinese bream was $1.39 \pm 0.03,2.64 \pm 0.22$ and $4.28 \pm 0.70$ torr at $10,20,30^{\circ} \mathrm{C}$, respectively. There were significant differences among all three temperature groups $(P<0.05)$.

\subsection{Metabolites}

\subsubsection{Liver glycogen}

The liver glycogen content under normoxia decreased significantly as the temperature increased 
for both fish species $(P<0.05)$ (Fig. 4a). After hypoxia exposure, only the glycogen content at $20{ }^{\circ} \mathrm{C}$ in crucian carp significantly decreased $(P<0.05)$, whereas there was no significant difference between the other groups. The liver glycogen content of crucian carp under normoxia was higher than that of Chinese bream at all three temperatures $(P<0.05)$.

\subsubsection{Muscle glycogen}

There was no significant difference in the muscle glycogen content of crucian carp among all three temperature groups under normoxia. However, the muscle glycogen content of Chinese bream under normoxia decreased significantly as the temperature increased from 10 to $20^{\circ} \mathrm{C}$, but it increased significantly as the temperature increased from 20 to $30^{\circ} \mathrm{C}(P<0.05)$ (Fig. $\left.4 \mathrm{~b}\right)$. After hypoxia treatment, the muscle glycogen content at both 20 and $30{ }^{\circ} \mathrm{C}$ decreased significantly in both fish species $(P<0.05)$. The muscle glycogen content of crucian carp under normoxia at $10{ }^{\circ} \mathrm{C}$ was significantly lower than that of Chinese bream $(P<0.05)$, whereas the muscle glycogen content of crucian carp under normoxia at both 20 and $30{ }^{\circ} \mathrm{C}$ was significantly higher than that of Chinese bream $(P<0.05)$.

\subsubsection{Liver glucose}

The liver glucose content of crucian carp under normoxia increased significantly as the temperature increased $(P<0.05)$, but there was no significant difference in the liver glucose content of Chinese bream under normoxia at any of the three temperatures (Fig. 4c). After hypoxia treatment, the liver glucose content of crucian carp at both 10 and $20{ }^{\circ} \mathrm{C}$ and that of Chinese bream at $10{ }^{\circ} \mathrm{C}$ increased significantly $(P<0.05)$. The liver glucose content of crucian carp under normoxia at $10{ }^{\circ} \mathrm{C}$ was significantly lower than that of Chinese bream $(P<0.05)$.

\subsubsection{Muscle glucose}

The muscle glucose content of crucian carp under normoxia decreased significantly as the temperature increased $(P<0.05)$. However, the muscle glucose content of Chinese bream under normoxia increased significantly as the temperature increased from 10 to $20{ }^{\circ} \mathrm{C}$, whereas it decreased significantly as the temperature increased from 20 to $30{ }^{\circ} \mathrm{C}(P<0.05)$ (Fig. 4d). After hypoxia treatment, the muscle glucose content of crucian carp was significantly increased at $30{ }^{\circ} \mathrm{C}(P<0.05)$, whereas that of Chinese bream was significantly decreased at $20{ }^{\circ} \mathrm{C}(P<$ 0.05). There was no significant difference in the muscle glucose content of either fish species at any of the three temperatures under normoxia. 


\section{$\underline{3.2 .5 \text { Muscle lactate }}$}

There was no significant difference in the muscle lactate content of crucian carp at any of the three temperatures under normoxia. However, the muscle lactate content of Chinese bream under normoxia decreased significantly as the temperature increased from 10 to $20^{\circ} \mathrm{C}$, whereas it increased significantly as the temperature increased from 20 to $30{ }^{\circ} \mathrm{C}(P<0.05)$ (Fig. 4e). After hypoxia exposure, the muscle lactate content significantly increased in both fish species at all temperatures $(P<0.05)$. There was no significant difference in the muscle lactate content between crucian carp and Chinese bream at any of the three temperatures.

\subsubsection{Brain lactate}

The brain lactate content of crucian carp under normoxia was significantly increased $(P<0.05)$, but the brain lactate content of Chinese bream under normoxia significantly decreased, as the temperature increased $(P<0.05)$ (Fig. 4f). After hypoxia exposure, the brain lactate content of both fish species was significantly increased $(P<0.05)$. Only the brain lactate content under normoxia at $30{ }^{\circ} \mathrm{C}$ of crucian carp was significantly lower than that of Chinese bream $(P<$ $0.05)$.

\subsubsection{Plasma lactate}

The plasma lactate content of both fish species under normoxia increased significantly as the temperature increased $(P<0.05)$ (Fig. $4 \mathrm{~g})$. After hypoxia exposure, the plasma lactate content of all groups of crucian carp was significantly increased $(P<0.05)$, whereas only the plasma lactate content of the $10{ }^{\circ} \mathrm{C}$ group of Chinese bream was significantly increased $(P<0.05)$. At any acclimated temperature, the plasma lactate content of normoxia groups of crucian carp was significant lower than those of Chinese bream $(P<0.05)$.

\subsubsection{Liver lactate}

The liver lactate content of crucian carp decreased as the temperature increased, but there was no significant difference in the liver lactate content of Chinese bream at any of the three temperature groups under normoxia (Fig. 4h). After hypoxia exposure, the liver lactate content of crucian carp at 20 and $30^{\circ} \mathrm{C}$ was significantly increased $(P<0.05)$, whereas only the liver lactate content of Chinese bream at $10{ }^{\circ} \mathrm{C}$ was significantly increased $(P<0.05)$. The liver lactate contents of crucian carp under normoxia at 10 and $20{ }^{\circ} \mathrm{C}$ were significantly higher than those of Chinese bream $(P<0.05)$. 


\section{Discussion}

The aims of the present study were to investigate the effect of temperature on hypoxia tolerance and the underlying biochemical mechanisms in crucian carp and Chinese bream. We found that compared to Chinese bream, crucian carp possessed larger tissue glycogen stores, as well as higher lactate tolerance and clearance ability, all of which contributed to a higher hypoxia tolerance. The elevation of temperature had no effect on the hypoxia tolerance of crucian carp but profoundly decreased the hypoxia tolerance of Chinese bream. The different responses to thermal variation between the species was due to the greater recruitment of tissue glycogen, resulting in a higher glucose content, which comprises the cellular fuel available to provide energy via anaerobic pathways during hypoxia, the higher liver lactate disposal capacity, which avoids self-lactate poisoning, and the smaller increase in $\dot{M} \mathrm{O}_{2 \text { rout }}$, which reduces the oxygen demand, at higher temperatures in crucian carp than in Chinese bream.

\subsection{The effect of temperature on the $\dot{M}_{2 \text { rout }}$ of the two cyprinids}

Temperature is an 'ecological driving force' in aquatic ecosystems: It significantly influences all levels of biological organization (Guderley, 2004). In this study, the $\dot{M} \mathrm{O}_{2 \text { rout }}$ displayed an increasing trend with rising temperature in both cyprinids, as expected. This result was in agreement with most previous studies of fish species (Pang et al., 2010, 2013; Sørensen et al., 2014). However, the $\dot{M} \mathrm{O}_{2 \text { rout }}$ of Chinese bream increased more profoundly with increasing temperature than that of crucian carp. There was no difference in the $\dot{M} \mathrm{O}_{2 \text { rout }}$ between crucian carp at 20 and $30^{\circ} \mathrm{C}$, suggesting that some compensatory mechanisms offset the increased enzyme-catalyzed metabolic rate associated with the increase in temperature (Clarke et al., 1992). This compensation may partially explain why hypoxia tolerance of crucian carp was was less affected by temperature change than Chinese bream.

\subsection{The effect of temperature on the hypoxia tolerance of the two cyprinids}

$P_{\text {crit }}$ is often used as a proxy measure of hypoxia tolerance. In the present study, the $P_{\text {crit }}$ varied from 17 to 26 depending to the acclimated temperature. These values were generally lower than those of most other species, such as rainbow trout $\left(P_{\text {crit }}=27\right.$ torr at $20{ }^{\circ} \mathrm{C}$, Ott et al., 1980$)$, 
Amazonian oscar (Astronotus ocellatus, $P_{\text {crit }}=46.40$ torr at $28{ }^{\circ} \mathrm{C}$, Scott et al., 2008) and largemouth bass (Micropterus salmoides, $P_{\text {crit }}=39.01$ torr at $30^{\circ} \mathrm{C}$, Yamanaka et al., 2007). The $P_{\text {crit }}$ of crucian carp and Chinese bream approximated that of hypoxia-tolerant fish species, such as European freshwater eel (Anguilla anguilla) $\left(P_{\text {crit }}=25\right.$ torr at $25^{\circ} \mathrm{C}$, Cruz-Neto and Steffensen, 1997) and goldfish $\left(P_{\text {crit }}=22.97\right.$ torr at $12{ }^{\circ} \mathrm{C}$, Fu et al., 2011). The relatively lower $P_{\text {crit }}$ values of juvenile cyprinids indicated their remarkable capability to tolerate hypoxia. With respect to these two species, the lower $P_{\text {crit }}$ value of crucian carp compared to Chinese bream suggested that crucian carp exhibits greater hypoxia tolerance than Chinese bream.

Although the elevation of temperature leads to the increase in $\dot{M}_{2 \text { rout, }}$ which corresponds to the oxygen demand, our studies found that the $P_{\text {crit }}$ of crucian carp was not increased as expected. Furthermore, the $P_{\text {crit }}$ of Chinese bream decreased by $21.47 \%$ at the increased temperature. This result suggests that the oxygen uptake efficiency may improve at higher temperatures, possibly due to increased gill ventilation, elevated blood hemoglobin concentration $(\mathrm{Hb})$, improved $\mathrm{Hb}-\mathrm{O}_{2}$ binding affinity, upregulated cardiovascular function and more efficient mitochondrial $\mathrm{O}_{2}$ turnover (Mandic et al., 2009; Farrell and Richards, 2009; Speers-Roesch et al., 2012a; Speers-Roesch et al., 2012b). In addition to these adaptations, crucian carp also exhibited gill remodeling to increase the functional surface area of the gills in response to increased temperature and/or decreased oxygen availability to improve the oxygen uptake efficiency (Dhillon et al., 2013).

Under hypoxic conditions, fish perform ASR to obtain oxygen from the water surface to avoid the disadvantageous environment (Richards, 2010). Aerial respiration can alleviate some of the physiological consequences of hypoxia exposure but requires costly physiological and behavioral attributes (Sloman et al., 2006). In general, hypoxia tolerant fish may delay initiating ASR in favor of reducing metabolic demand (Yoshiyama et al., 1995). However, our results revealed that the $\mathrm{ASR}_{\text {crit }}$ of crucian carp was higher than that of Chinese bream. This unusual phenomenon may allow crucian carp to endure hypoxia in an active rather than comatose state (Nilsson and Renshaw, 2004). A similar result was also found in sculpins (Mandic et al., 2009), in which more hypoxia tolerant sculpins initiated ASR at higher oxygen tension values than less hypoxia tolerant sculpins. These findings suggest that ASR may be not an appropriate indicator of hypoxia tolerance in active fish species (Dhillon et al., 2013); at least, the ASR is not a 
reliable differentiator between fish species that exhibit distinct ecological properties, e.g. active vs sluggish species or bold vs timid species.

In contrast to the response of $P_{\text {crit }}$ to changes in temperature, the total number of ASR and $\mathrm{ASR}_{\text {crit }}$ increased significantly in Chinese bream (this phenomenon was not observed in crucian carp). Similar results were found for LOE. These results clearly demonstrated that the hypoxia tolerance of Chinese bream decreased as the temperature increased, whereas the hypoxia tolerance of crucian carp was much less affected by the temperature changed. Thus, Chinese bream be more sensitive to temperature change than crucian carp and thermal change in near future in their natural habitat may show more profound effect in Chinese bream than crucian carp.

\subsection{The effect of temperature and hypoxia exposure on the metabolites'content}

The tissues for metabolites measurements were sampled immediately after fish showed LOE behavior in both fish species in the present study. However, the fish sampled for metabolic analysis following hypoxia were exposed to different regimes due to the great difference in hypoxia tolerance between two species, i.e. hypoxia $v s$ anoxia.

\subsubsection{Hypoxia tolerance of the two cyprinids}

The liver is a glucose-utilizing, -producing and -storing organ (Lermen et al., 2004). It is generally acknowledged that liver glycogen represents the major carbohydrate store in the fish body that plays an important role in fish survival under hypoxic conditions (Dunn and Hochachka, 1986; Nilsson and Renshaw, 2004). The liver glycogen content of crucian carp was much higher than that of Chinese bream and other vertebrates studied (Nilsson and Renshaw, 2004). Furthermore, the muscle glycogen which plays an important role in maintaining cellular energy balance during severe hypoxia (Lutz and Nilsson, 1997) of crucian carp at high temperatures was also greater than that of Chinese bream. The enormous tissue glycogen reserve of crucian carp contributes to its extremely high hypoxia tolerance.

It has been found that accumulated brain lactate is a systemic toxin that ultimately results in death under hypoxic conditions (Cox, 1974). In the present study, the brain lactate content of crucian carp after hypoxia exposure was higher than that of Chinese bream at all three temperatures. This result suggested that crucian carp tolerate higher lactate levels than Chinese 
bream. Furthermore, crucian carp displayed a higher plasma lactate content after hypoxia exposure than Chinese bream for all groups, and the liver lactate content increased after hypoxia exposure at 20 and $30{ }^{\circ} \mathrm{C}$ in crucian carp but not in Chinese bream. These results suggested that crucian carp can cope with lactate from tissues more efficiently by transporting it to the liver. Thus, a higher lactate tolerance and lactate clearance ability (which slows the accumulation of lactate in the brain and muscle and avoids self-poisoning), along with the higher tissue glycogen reserve, contributed to the higher hypoxia tolerance of crucian carp than Chinese bream.

\subsubsection{The effect of temperature on the hypoxia tolerance of the two cyprinids}

Temperature is known to affect the processes of energy storage, turnover and utilization and therefore the oxygen requirement in fish species. It has been found that in most fish species, the hypoxia tolerance decreases with increasing temperature as a consequence of increased $\dot{M} \mathrm{O}_{2 \text { rout }}$, corresponding to oxygen demand (Sørensen et al., 2014). A similar result was found in Chinese bream in this study. However, the hypoxia tolerance of crucian carp was relatively independent of temperature changes. Although the $\dot{M} \mathrm{O}_{2 \text { rout }}$ of crucian carp was less sensitive to temperature changes than Chinese bream, this finding may also have been possible partially due to the more efficient utilization of tissue glycogen under hypoxia at high temperatures, as suggested by the greater decrease in liver and muscle glycogen content after hypoxia exposure in crucian carp than in Chinese bream. The utilization of liver glycogen in crucian carp but not in Chinese bream at high temperatures guaranteed a sufficient supply of glucose, which is the only cellular fuel available during hypoxia. Thus, the muscle and liver glucose contents increased by $16-83 \%$ after hypoxia exposure at 20 and $30{ }^{\circ} \mathrm{C}$. However, in Chinese bream, only the muscle glycogen content decreased, and the tissue glucose content displayed no increase, even decreasing (muscle glucose at $20{ }^{\circ} \mathrm{C}$ ) at higher temperatures. The muscle glycogen content was profoundly depleted after hypoxia exposure, suggesting that substrate shortage may also be one limiting factor when Chinese bream are exposed to a hypoxic high-temperature environment. Hypoxia exposure leads to a profound increase in the muscle and brain lactate levels in both crucian carp and Chinese bream, which was in agreement with many other fish species (Dunn and Hochachka, 1986; Mandic et al., 2009). In crucian carp, the plasma lactate content 
increased in all three temperature groups, indicating that the accumulated tissue lactate was released into the plasma (Li et al., 2007; Kieffer, 2000). The released lactate was then transported to liver, which resulted in an increased liver lactate content in both the 20 and $30{ }^{\circ} \mathrm{C}$ groups. However, in Chinese bream, there was no change in the plasma or liver lactate content after hypoxia exposure at high temperatures. This result suggested that crucian carp exhibit greater tissue lactate clearance ability than Chinese bream. The improved tissue lactate managing ability in crucian carp at high temperatures might also be one reason why crucian carp were less sensitive to temperature increases than Chinese bream. It is interesting that in Chinese bream, contrary to the 20 and $30{ }^{\circ} \mathrm{C}$ groups, the plasma and liver lactate levels increased after hypoxia exposure in the $10{ }^{\circ} \mathrm{C}$ group. This unusual result requires further investigation. Furthermore, the brain lactate content of the $30{ }^{\circ} \mathrm{C}$ group was lower that of the 10 and $20{ }^{\circ} \mathrm{C}$ groups, suggesting that the lactate tolerance may be decreased at high temperatures in Chinese bream. Thus, in Chinese bream, the reduced lactate clearance ability and lactate tolerance resulted in a profound decrease in hypoxia tolerance with the increasing temperature. In addition, the ability of crucian carp to convert glycolytic metabolic byproducts to ethanol, which is efficiently released into the water, at higher temperatures may also play a role in their preservation of hypoxia tolerance at high temperatures (Van Waarde, 1991).

In conclusion, crucian carp exhibited higher hypoxia tolerance than Chinese bream due to its higher reserve of muscle and liver glycogen stores, more efficient recruitment of tissue glycogen during hypoxia and higher lactate tolerance and clearance ability. The hypoxia tolerance of crucian carp remained stable with increasing temperature due to its relative insensitivity of $\dot{M} \mathrm{O}_{2 \text { rout }}$ to temperature increases, its improved utilization of tissue glycogen stores to provide cellular fuel during hypoxia and its greater tissue lactate clearance ability at higher temperatures. However, in Chinese bream, the hypoxia tolerance decreased with increasing temperature, possibly due to the depletion of available tissue glycogen and thus a shortage of cellular fuel and its decreased lactate tolerance and clearance ability at higher temperatures.

Acknowledgments. This study was funded by grants from the National Science Foundation of China (NSFC 31172096) and the Key Project of the Natural Science Foundation of CQ 
(cstc2013jjB20003).

\section{References}

Barnes, R.K., King, H., Carter, C.G., 2011. Hypoxia tolerance and oxygen regulation in Atlantic salmon, Salmo salarfrom a Tasmanian population. Aquaculture 318, 397-401.

Chapman, L.J., Chapman, C.A., Nordlie, F.G., Rosenberger, A.E., 2002. Physiological refugia: swamps, hypoxia tolerance and maintenance of fish diversity in the Lake Victoria region. Comp. Biochem. Physiol. A 133, 421-437.

Chapman, L.J., Kaufman, L.S., Chapman, C.A., Mckenzie, F.E., 1995. Hypoxia tolerance in twelve species of East African cichlids: potential for low oxygen refugia in Lake Victoria. Conserv. Biol. 9, 1274-1288.

Chen, B.J., CAO, Z.D., Fu, S.J., Wang, Y.X., 2010. Temperature effect on rest metabolic rate and hypoxia tolerance in Chinese bream (Parabramis pekinensis).Chin. J. Zool. 45, 1-8.

Clarke, M.E., Calvi, C., Domeier, M., Edmonds, M., Walsh, P.J., 1992. Effects of nutrition and temperature on metabolic enzyme activities in larval and juvenile red drum, Sciaenops ocellatus, and lane snapper, Lutjanus synagris. Mar. Biol. 112, 31-36.

Collins, G.M., Clark, T.D., Rummer, J.L., Carton, A.G., 2013. Hypoxia tolerance is conserved across genetically distinct sub-populations of an iconic, tropical Australian teleost (Lates calcarifer). Conserv. Physiol. 1, cot029.

Coutant, C.C., 1969. Temperature, reproduction and behavior. Chesapeake Sci. 10, 247-261.

Cox, D.K., 1974. Effects of three heating rates on the critical thermal maximum of bluegill. In: Gibbons, W., Sharitz, R.R. (Eds.), Thermal Ecology. National Technical Information Service, Springfield, IL, pp. 158-163.

Cruz-Neto, A.P., Steffensen, J.F., 1997. The effects of acute hypoxia and hypercapnia on oxygen consumption of the freshwater European eel. J. Fish Biol. 50, 759-769.

Currie, R.J., Bennett, W.A., Beitinger, T.L., Cherry, D.S., 2004. Upper and lower temperature tolerances of juvenile freshwater game-fish species exposed to 32 days of cycling temperatures. Hydrobiologia $532,127-136$.

Dhillon, R.S., Yao, L.L., Matey, V., Chen, B.J., Zhang, A.J., Cao, Z.D., Fu, S.J., Brauner., C.J., Wang, Y.X., Richards, J.G., 2013. Interspecific differences in hypoxia-induced gill remodeling in carp. Physiol. Biochem. Zool. 86, 727-739.

Diaz, R.J., Breitburg, D.L., 2009. The hypoxic environment. Fish Physiol 27, 1-23. Diaz, R.J., Rosenberg, R., 1995. Marine benthic hypoxia: A review of its ecological effects and the behavioural responses of benthic macrofauna. Oceanogr. Mar. Biol. Ann. Rev. 33, 245-303.

Diaz, R.J., Rosenberg, R., 2008. Spreading dead zones and consequences for marine ecosystems. Sci. 321, 926-929.

Dunn, J.F., Hochachka, P.W., 1986. Metabolic responses of trout (Salmo gairdneri) to acute environmental hypoxia. J. Exp. Biol. 123, 229-242.

Farrell, A. P., Richards, J. G., 2009. An integrative synthesis of the responses of fish to hypoxia. Fish Physiol. 27, 448-503.

Ficke, A.D., Myrick, C.A., Hansen, L.J., 2007. Potential impacts of global climate change on freshwater fisheries. Rev. Fish. Biol. Fisher 17, 581-613.

Fu, S.J., Brauner, C.J., Cao, Z.D., Richards, J.G., Peng, J.L., Dhillon, R., Wang, Y.X., 2011.The effect of acclimation to hypoxia and sustained exercise on subsequent hypoxia tolerance and swimming 
performance in goldfish (Carassius auratus). J. Exp. Biol. 214, 2080-2088.

Fu, S.J., Yan, G.J., Cao, Z.D., Fu,C., Zhang, A.J., Pang, X., 2014. Interspecies variation in hypoxia tolerance, swimming performance and plasticity in cyprinids that prefer different habitats. J. Exp. Biol. 217, 590-597.

Graham, J.B., 1990. Ecological, evolutionary, and physical factors influencing aquatic animal respiration. Am. Zool. 30, 137-146.

Guderley, H., 2004. Metabolic responses to low temperature in fish muscle. Biol. Rev. 79, 409-427.

Huang, R.B., Ding, C.Y., Lin, H.Y., 1995. Biochemistry Experiments. World Publishing Co., Ltd., Beijing 109-110.

Karim, M.R., Sekini, M., Ukita, M., 2003. A model of fish preference and mortality under hypoxic water in the coastal environment. Mar. Pollut. Bull. 47, 25-29.

Kieffer, J.D., 2000. Limits to exhaustive exercise in fish. Comp. Biochem. Physiol. A126, 161-179.

Kramer, D.L., 1983. Aquatic surface respiration in thefishes of Panama: distribution in relation to risk of hypoxia. Environ. Biol. Fish. 8, 49-54.

Lermen, C.L., Lappe, R., Crestani, M., Vieira, V.P., Gioda, C.R., Schetinger, M.R. C., Morsch, V.M., 2004. Effect of different temperature regimes on metabolic and blood parameters of silver catfish Rhamdia quelen. Aquaculture 239, 497-507.

Li, L., Cao, Z.D., Fu, S.J., 2007. Lactate, glycogen and glucose levels of juvenile Chinese catfish (Silurus asotus Linnaeus). Acta. Hydrobiol. Sinica. 31, 880-885.

Lutz, P.L., Nilsson, G., 1997. Contrasting strategies for anoxia brain survivial - glycolysis up or down. J. Exp.Biol. 200, 411-419.

Mandic, M., Speers-Roesch, B., Richards, J.G., 2013. Hypoxia tolerance in sculpins is associated with high anaerobic enzyme activity in brain but not in liver or muscle. Physiol. Biochem. Zool. 86, 92-105.

Mandic, M., Todgham, A.E., Richards, J.G., 2009. Mechanisms and evolution of hypoxia tolerance in fish. Proc. Roy. Soc. B 276, 735-744.

Martínez, M.L., Raynard, E.L., Rees, B.B., Chapman, L.J. , 2011. Oxygen limitation and tissue metabolic potential of the African fish Barbus neumayeri: roles of native habitat and acclimatization. BMC Ecol. 11, 2.

Nilsson, G.E., Östlund-Nilsson, S., 2008. Does size matter for hypoxia tolerance in fish? Biol. Rev. 83, 173-189.

Nilsson, G.E., Renshaw, G.M., 2004. Hypoxic survival strategies in two fishes: extreme anoxia tolerance in the North European crucian carp and natural hypoxic preconditioning in a coral-reef shark. J. Exp. Biol. 207, 3131-3139

Ott, M.E., Heisler, N., Ultsch, G.R., 1980. A re-evaluation of the relationship between temperature and the critical oxygen tension in freshwater fishes. Comp. Biochem. Physiol. A 67, 337-340.

Paladino, F.V., Spotila, J.R., Schubauer, J.P., Kowalski, K.T., 1980. The critical thermal maximum: A technique used to elucidate physiological stress and adaptation in fishes. Rev. Can. Biol. 39, $115-122$

Pang, X., Cao, Z.D., Peng, J.L., Fu, S.J., 2010. The effects of feeding on the swimming performance and metabolic response of juvenile southern catfish, Silurus meridionalis acclimated at different temperatures. Comp. Biochem. Physiol. A155, 253-258.

Pang, X., Yuan, X.Z., Cao, Z.D., Fu, S.J., 2013. The effects of temperature and exercise training on swimming performance in juvenile qingbo (Spinibarbus sinensis). J. Comp. Physiol. B183, 99-108.

Pörtner, H.O., Grieshaber, M.K., 1993. In Bicudo, J.E.P.W. (Ed), Critical $\mathrm{P}_{\mathrm{O} 2}(\mathrm{~s})$ in oxyconforming and oxyregulating animals: Gas exchange, metabolic rate and the mode of energy production. The Vertebrate Gas Transport Cascade: Adaptations to Environment and Mode of Life. CRC, Boca 
Raton, FL, Pp. 330-357.

Rabalais, N.N., Turner, R.E., Díaz, R.J., Justić, D., 2009. Global change and eutrophication of coastal waters. ICES. J. Mar. Sci. 66, 1528-1537.

Richards, J.G., Farrell, A.P., Brauner, C.J. 2009. Hypoxia. Fish Physiol 27, 528pp.

Richards, J.R., 2010. Physiological, behavioral and biochemical adaptations of intertidal fishes to hypoxia. J. Exp. Biol. 214, 191-199.

Roze, T., Christen, F., Amerand, A., Claireaux, G., 2013. Trade-off between thermal sensitivity, hypoxia tolerance and growth in fish. J. Therm. Biol. 38, 98-106.

Scott, G.R., Wood, C.M., Sloman, K.A., Iftikar, F.I., Boeck, G.D., Almeida-Val .V.M.F., Val, A.L., 2008. Respiratory responses to progressive hypoxia in the Amazonian oscar, Astronotus ocellatus. Resp. Physiol. Neurobi. 162, 109-116.

Seibel, B.A., 2011. Critical oxygen levels and metabolic suppression in oceanic oxygen minimum zones. J. Exp. Biol. 214, 326-336.

Shingles, A., McKenzie, D.J., Claireaux, G., Domenici, P., 2005. Reflex cardioventilatory responses to hypoxia in the flathead gray mullet (Mugil cephalus) and their behavioral modulation by perceived threat of predation and water turbidity. Physiol. Biochem. Zool. 78, 744-755.

Sloman, K.A., Wood, C.M., Scott, G.R., Wood, S., Kajimura, M., Johannsson, O.E., AlmeidaVal, V.M.F., Val, A.L., 2006. Tribute to R. G. Boutilier: the effect of size on the physiological and behavioural responses of oscar, Astronotus ocellatus, to hypoxia. J. Exp. Biol. 209, 1197-1205.

Soares, M.G.M., Menesez, N.A., Junk, W.J., 2006. Adaptations of fish to oxygen depletion in a central Amazonian floodplain lake. Hydrobiologia 568, 357-367.

Sollid, J., De Angelis, P., Gundersen, K., Nilsson, G.E., 2003. Hypoxia induces adaptive and reversible gross morphological changes in crucian carp gills. J. Exp. Biol. 206, 3667-3673.

Sørensen, C., Munday, P.L., Nilsson, G.E., 2014. Aerobic vs. anaerobic scope: sibling species of fish indicate that temperature dependence of hypoxia tolerance can predict future survival. Global. Change. Biol. 20, 724-729.

Speers-Roesch, B., Brauner, C.J., Farrell, A.P., Hickey, A.J., Renshaw, G.M., Wang, Y. S., Richards, J.G., 2012a. Hypoxia tolerance in elasmobranchs. II. Cardiovascular function and tissue metabolic responses during progressive and relative hypoxia exposures. J. Exp. Biol. 215, 103-114.

Speers-Roesch, B., Richards, J.G., Brauner, C.J., Farrell, A.P., Hickey, A.J., Wang, Y. S., Renshaw, G.M., 2012b. Hypoxia tolerance in elasmobranchs. I. Critical oxygen tension as a measure of blood oxygen transport during hypoxia exposure. J. Exp. Biol. 215, 93-102.

Takasusuki, J., Fernandes, M.N., Severi, W., 1998. The occurrence of aerial respiration in Rhinelepis strigosa during progressive hypoxia. J. Fish Biol. 52, 369-379.

Urbina, M.A., Forster, M.E., Glover, C.N., 2011. Leap of faith: Voluntary emersion behaviour and physiological adaptations to aerial exposure in a non-aestivating freshwater fish in response to aquatic hypoxia. Physiol. Behav. 103, 240-247.

Van Waarde, A., 1991. Alcoholic fermentation in multicellular organisms. Physiol. Zool. 64, 895-920.

Yamanaka, H., Kohmatsu, Y., Yuma, M., 2007. Difference in the hypoxia tolerance of the round crucian carp and largemouth bass: implications for physiological refugia in the macrophyte zone. Ichthyol. Res. 54, 308-312.

Yang, H., Cao, Z.D., Fu, S.J., 2013. The effects of diel-cycling hypoxia acclimation on the hypoxia tolerance, swimming capacity and growth performance of southern catfish (Silurus meridionalis). Comp. Biochem. Physiol. A165, 131-138.

Yeager, D.P., Ultsch, G.R., 1989. Physiological regulation and conformation: A basic program for the determination of critical points. Physiol. Zool. 62, 888-907.

Yoshiyama, R.M., Valpey, C.J., Schalk, L.L, Oswald, N.M., Vaness, K.K., Lauritzen, D., Limm, M., 1995. 
Differential propensities for aerial emergence in intertidal sculpins (Teleostei Cottidae). J. Exp. Mar. Biol. Ecol. 191, 195-207.

Zhang, L.X., Zhang, T.F., Li, L.Y., 1997. Biochemistry Experiments and Technology. High Education Press, Beijing 422-427.

Zhang, W., Cao, Z.D., Peng, J.L., Chen, B.J., Fu, S.J., 2010. The effects of dissolved oxygen level on the metabolic interaction between digestion and locomotion in juvenile southern catfish (Silurus meridionalis Chen). Comp. Biochem. Physiol. A157, 212-219.

\section{Captions}

Fig. 1. The effect of oxygen tension on the routine metabolic rate $\left(\dot{M} \mathrm{O}_{2 \text { rout }}, \mathrm{mg} \mathrm{O}_{2} \mathrm{~kg}^{-1} \mathrm{~h}^{-1}\right)$ in juvenile crucian carp (Fig. 1A) and Chinese bream (Fig. 1B) at three acclimated temperatures (n $=8$ for each group).

Fig. 2. The effect of temperature and oxygen tension on the total number of aquatic surface respirations (occurrences) of successive $5 \mathrm{~min}$ in juvenile crucian carp (Fig. 2A) and Chinese bream (Fig. 2B).

Fig. 3. The effect of temperature on the critical oxygen tension for aquatic surface respiration $\left(\mathrm{ASR}_{\text {crit }}\right.$, torr) in juvenile crucian carp and Chinese bream ( $\mathrm{n}=8$ for each group). ${ }^{\mathrm{a}, \mathrm{b}, \mathrm{c}}$ : different letters indicate a significant difference between the different treatment groups $(P<0.05)$. *: indicates a significant difference between the two species $(P<0.05)$.

Fig. 4. The effects of temperature and hypoxia (post-LOE) on the metabolite levels in different tissues from juvenile crucian carp and Chinese bream ( $\mathrm{n}=8$ for each group). ${ }^{\mathrm{x}, \mathrm{y}, \mathrm{z}}$ and ${ }^{\mathrm{a}, \mathrm{b}, \mathrm{c}}$ : different letters indicate a significant difference under normoxia between the different temperature groups of crucian carp and Chinese bream, respectively $(P<0.05)$. ${ }^{\text {: }}$ indicates a significant difference between normoxia and hypoxia exposure $(P<0.05)$. *: indicates a significant difference between the two species $(P<0.05)$. 
Table 1 . The effect of temperature on the $\dot{M} \mathrm{O}_{2 \text { rout }}$ and the $P_{\text {crit }}$ in juvenile crucian carp and Chinese bream based on two-way ANOVA (mean \pm S.E.M., $\mathrm{n}=8$ ).

\begin{tabular}{|c|c|c|c|c|c|c|c|c|}
\hline \multirow{2}{*}{\multicolumn{2}{|c|}{ Treatment }} & \multirow{2}{*}{$10^{\circ} \mathrm{C}$} & \multirow{2}{*}{$20{ }^{\circ} \mathrm{C}$} & \multirow{2}{*}{$30^{\circ} \mathrm{C}$} & \multicolumn{4}{|c|}{ Significance } \\
\hline & & & & & $\begin{array}{c}\text { Covariate (body } \\
\text { mass) }\end{array}$ & Species & Temperature & $\mathrm{S} \times \mathrm{T}$ \\
\hline \multirow{2}{*}{$\begin{array}{l}\text { Body mass } \\
\text { (g) }\end{array}$} & Crucian carp & $7.60 \pm 0.19 *$ & $7.13 \pm 0.16^{*}$ & $7.23 \pm 0.17 *$ & \multirow{2}{*}{ I } & \multirow{2}{*}{$\begin{array}{c}\mathrm{df}=1 \\
\mathrm{~F}=67.71 \\
P=0.000\end{array}$} & \multirow{2}{*}{$\begin{array}{c}\mathrm{df}=2 \\
\mathrm{~F}=2.160 \\
P=0.119\end{array}$} & \multirow{2}{*}{$\begin{array}{c}\mathrm{df}=2 \\
\mathrm{~F}=0.105 \\
P=0.901\end{array}$} \\
\hline & Chinese bream & $6.14 \pm 0.16$ & $5.84 \pm 0.26$ & $5.79 \pm 0.28$ & & & & \\
\hline \multirow{2}{*}{$\begin{array}{c}\dot{M} \mathrm{O}_{2 \text { rout }} \\
\left(\mathrm{mg} \cdot \mathrm{kg}^{-1} \cdot \mathrm{h}^{-1}\right)\end{array}$} & Crucian carp & $126.4 \pm 9.6^{\mathrm{a}^{*}}$ & $217.9 \pm 14.0^{\mathrm{b}}$ & $204.4 \pm 19.9^{\mathrm{b}^{*}}$ & \multirow{2}{*}{$\begin{array}{c}\mathrm{df}=1 \\
\mathrm{~F}=6.140 \\
P=0.017\end{array}$} & \multirow{2}{*}{$\begin{array}{c}\mathrm{df}=1 \\
\mathrm{~F}=0.008 \\
P=0.929\end{array}$} & \multirow{2}{*}{$\begin{array}{c}\mathrm{df}=2 \\
\mathrm{~F}=52.13 \\
P=0.000\end{array}$} & \multirow{2}{*}{$\begin{array}{c}\mathrm{df}=2 \\
\mathrm{~F}=8.549 \\
P=0.001\end{array}$} \\
\hline & Chinese bream & $84.87 \pm 6.6^{\mathrm{a}}$ & $221.5 \pm 16.9^{\mathrm{b}}$ & $283.2 \pm 14.6^{\mathrm{c}}$ & & & & \\
\hline \multirow{2}{*}{$Q_{10}$ of $\dot{M} \mathrm{O}_{2 \text { rout }}$} & Crucian carp & 1.72 & & 0.94 & \multirow{6}{*}{$\begin{array}{c}\mathrm{df}=1 \\
\mathrm{~F}=0.053 \\
P=0.819\end{array}$} & \multirow{6}{*}{$\begin{array}{c}\mathrm{df}=1 \\
\mathrm{~F}=8.000 \\
P=0.007\end{array}$} & \multirow{6}{*}{$\begin{array}{c}\mathrm{df}=2 \\
\mathrm{~F}=1.824 \\
P=0.174\end{array}$} & \multirow{6}{*}{$\begin{array}{c}\mathrm{df}=2 \\
\mathrm{~F}=0.743 \\
P=0.482\end{array}$} \\
\hline & Chinese bream & 2.61 & & 1.28 & & & & \\
\hline \multirow{2}{*}{$\begin{array}{l}P_{\text {crit }} \\
\text { (torr) }\end{array}$} & Crucian carp & $19.44 \pm 1.76$ & $17.96 \pm 1.20^{*}$ & $18.00 \pm 0.70$ & & & & \\
\hline & Chinese bream & $26.13 \pm 3.25$ & $23.96 \pm 1.72$ & $20.52 \pm 1.30$ & & & & \\
\hline \multirow{2}{*}{$Q_{10}$ of $P_{\text {crit }}$} & Crucian carp & 0.92 & & 1.00 & & & & \\
\hline & Chinese bream & 0.92 & & 0.86 & & & & \\
\hline
\end{tabular}

$\overline{\mathrm{a}, \mathrm{b}, \mathrm{c}}$ : values in each row without a common superscript are significantly different $(P<0.05)$.

*: indicates a significant difference between the two species $(P<0.05)$. 
Table 2. The effects of acclimated temperature and hypoxia (post-LOE) on the metabolite levels ( $\mu \mathrm{mol} \mathrm{g}^{-1}$ ) of various tissues from the two species based on three-way ANOVA

\begin{tabular}{|c|c|c|c|c|c|c|c|c|}
\hline & $\begin{array}{c}\text { Covariate } \\
\text { (body mass) }\end{array}$ & $\begin{array}{c}\text { Species } \\
(\mathrm{S})\end{array}$ & $\begin{array}{c}\text { Temperature } \\
\text { (T) }\end{array}$ & $\begin{array}{c}\text { Hypoxia } \\
(\mathrm{H})\end{array}$ & $\mathrm{S} \times \mathrm{T}$ & $\mathrm{S} \times \mathrm{H}$ & $\mathrm{T} \times \mathrm{H}$ & $\mathrm{S} \times \mathrm{T} \times \mathrm{H}$ \\
\hline $\mathrm{df}$ & 1 & 1 & 2 & 1 & 2 & 1 & 2 & 2 \\
\hline Liver glycogen & $\begin{array}{l}\mathrm{F}=0.360 \\
P=0.550\end{array}$ & $\begin{array}{l}\mathrm{F}=12.91 \\
P=0.001^{\#}\end{array}$ & $\begin{array}{l}\mathrm{F}=32.97 \\
P=0.000^{\#}\end{array}$ & $\begin{array}{l}\mathrm{F}=0.570 \\
P=0.452\end{array}$ & $\begin{array}{l}\mathrm{F}=0.515 \\
P=0.599\end{array}$ & $\begin{array}{l}\mathrm{F}=1.622 \\
P=0.206\end{array}$ & $\begin{array}{l}\mathrm{F}=1.863 \\
P=0.162\end{array}$ & $\begin{array}{l}\mathrm{F}=0.506 \\
P=0.605\end{array}$ \\
\hline Muscle glycogen & $\begin{array}{l}\mathrm{F}=0.792 \\
P=0.376\end{array}$ & $\begin{array}{l}\mathrm{F}=2.004 \\
P=0.161\end{array}$ & $\begin{array}{l}\mathrm{F}=51.03 \\
P=0.000^{\#}\end{array}$ & $\begin{array}{l}\mathrm{F}=28.41 \\
P=0.000^{\#}\end{array}$ & $\begin{array}{l}\mathrm{F}=21.66 \\
P=0.000^{\#}\end{array}$ & $\begin{array}{l}\mathrm{F}=0.143 \\
P=0.707\end{array}$ & $\begin{array}{l}\mathrm{F}=3.250 \\
P=0.044^{\#}\end{array}$ & $\begin{array}{l}\mathrm{F}=0.470 \\
P=0.627\end{array}$ \\
\hline Liver glucose & $\begin{array}{l}\mathrm{F}=1.242 \\
P=0.268\end{array}$ & $\begin{array}{l}\mathrm{F}=2.865 \\
P=0.094\end{array}$ & $\begin{array}{l}\mathrm{F}=3.639 \\
P=0.031^{\#}\end{array}$ & $\begin{array}{l}\mathrm{F}=42.85 \\
P=0.000^{\#}\end{array}$ & $\begin{array}{l}\mathrm{F}=8.939 \\
P=0.000^{\#}\end{array}$ & $\begin{array}{l}\mathrm{F}=6.414 \\
P=0.013^{\#}\end{array}$ & $\begin{array}{l}\mathrm{F}=9.528 \\
P=0.000^{\#}\end{array}$ & $\begin{array}{l}\mathrm{F}=0.461 \\
P=0.632\end{array}$ \\
\hline Muscle glucose & $\begin{array}{l}\mathrm{F}=0.594 \\
P=0.443\end{array}$ & $\begin{array}{l}\mathrm{F}=3.820 \\
P=0.054\end{array}$ & $\begin{array}{l}\mathrm{F}=7.109 \\
P=0.001^{\#}\end{array}$ & $\begin{array}{l}\mathrm{F}=0.291 \\
P=0.591\end{array}$ & $\begin{array}{l}\mathrm{F}=1.767 \\
P=0.177\end{array}$ & $\begin{array}{l}\mathrm{F}=9.311 \\
P=0.003^{\#}\end{array}$ & $\begin{array}{l}\mathrm{F}=2.050 \\
P=0.135\end{array}$ & $\begin{array}{l}\mathrm{F}=9.398 \\
P=0.000^{\#}\end{array}$ \\
\hline Muscle lactate & $\begin{array}{l}\mathrm{F}=0.481 \\
P=0.490\end{array}$ & $\begin{array}{l}\mathrm{F}=0.285 \\
P=0.595\end{array}$ & $\begin{array}{l}\mathrm{F}=14.50 \\
P=0.000^{\#}\end{array}$ & $\begin{array}{l}\mathrm{F}=39.58 \\
P=0.000^{\#}\end{array}$ & $\begin{array}{l}\mathrm{F}=0.381 \\
P=0.685\end{array}$ & $\begin{array}{l}\mathrm{F}=4.705 \\
P=0.033^{\#}\end{array}$ & $\begin{array}{l}\mathrm{F}=1.878 \\
P=0.159\end{array}$ & $\begin{array}{l}\mathrm{F}=1.558 \\
P=0.217\end{array}$ \\
\hline Brain lactate & $\begin{array}{l}\mathrm{F}=1.059 \\
P=0.306\end{array}$ & $\begin{array}{l}\mathrm{F}=15.98 \\
P=0.000^{\#}\end{array}$ & $\begin{array}{l}\mathrm{F}=3.989 \\
P=0.022^{\#}\end{array}$ & $\begin{array}{l}\mathrm{F}=230.7 \\
P=0.000^{\#}\end{array}$ & $\begin{array}{l}\mathrm{F}=7.694 \\
P=0.001^{\#}\end{array}$ & $\begin{array}{l}\mathrm{F}=25.98 \\
P=0.000^{\#}\end{array}$ & $\begin{array}{l}\mathrm{F}=6.226 \\
P=0.003^{\#}\end{array}$ & $\begin{array}{l}\mathrm{F}=4.138 \\
P=0.019^{\#}\end{array}$ \\
\hline Plasma lactate & $\begin{array}{l}\mathrm{F}=1.438 \\
P=0.234\end{array}$ & $\begin{array}{l}\mathrm{F}=0.732 \\
P=0.395\end{array}$ & $\begin{array}{l}\mathrm{F}=5.805 \\
P=0.004^{\#}\end{array}$ & $\begin{array}{l}\mathrm{F}=129.2 \\
P=0.000^{\#}\end{array}$ & $\begin{array}{l}\mathrm{F}=3.509 \\
P=0.034\end{array}$ & $\begin{array}{l}\mathrm{F}=68.300 \\
P=0.000^{\#}\end{array}$ & $\begin{array}{l}\mathrm{F}=5.410 \\
P=0.006^{\#}\end{array}$ & $\begin{array}{l}\mathrm{F}=0.365 \\
P=0.695\end{array}$ \\
\hline Liver lactate & $\begin{array}{l}\mathrm{F}=0.209 \\
P=0.649\end{array}$ & $\begin{array}{l}\mathrm{F}=182.10 \\
P=0.000^{\#}\end{array}$ & $\begin{array}{l}\mathrm{F}=56.98 \\
P=0.000^{\#}\end{array}$ & $\begin{array}{c}\mathrm{F}=116.7 \\
P=0.000 \#\end{array}$ & $\begin{array}{l}\mathrm{F}=93.79 \\
P=0.000^{\#}\end{array}$ & $\begin{array}{l}\mathrm{F}=102.1 \\
P=0.000^{\#}\end{array}$ & $\begin{array}{l}\mathrm{F}=60.80 \\
P=0.000^{\#}\end{array}$ & $\begin{array}{l}\mathrm{F}=116.9 \\
P=0.000^{\#}\end{array}$ \\
\hline
\end{tabular}

\#: indicates a significant difference $(P<0.05)$. 
a) Crucian carp $10{ }^{\circ} \mathrm{C}$

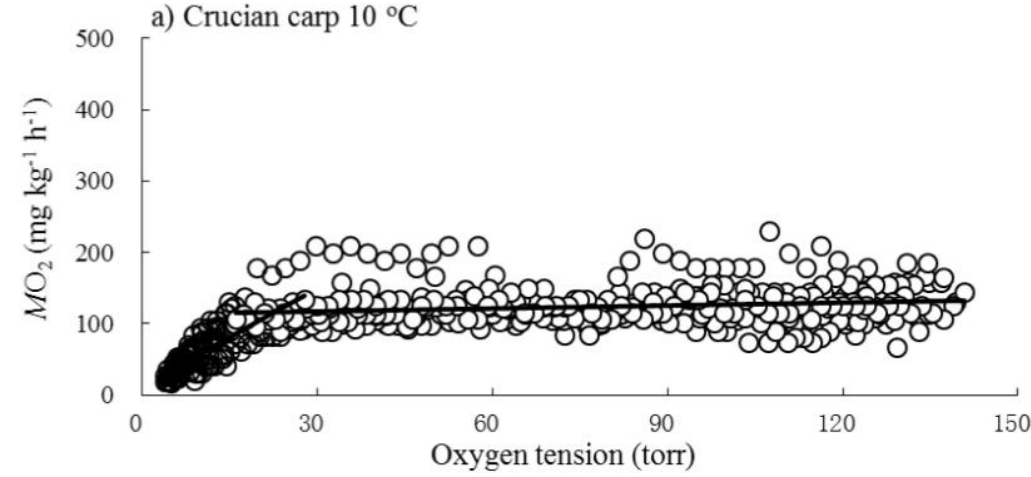

b) Crucian carp $20^{\circ} \mathrm{C}$
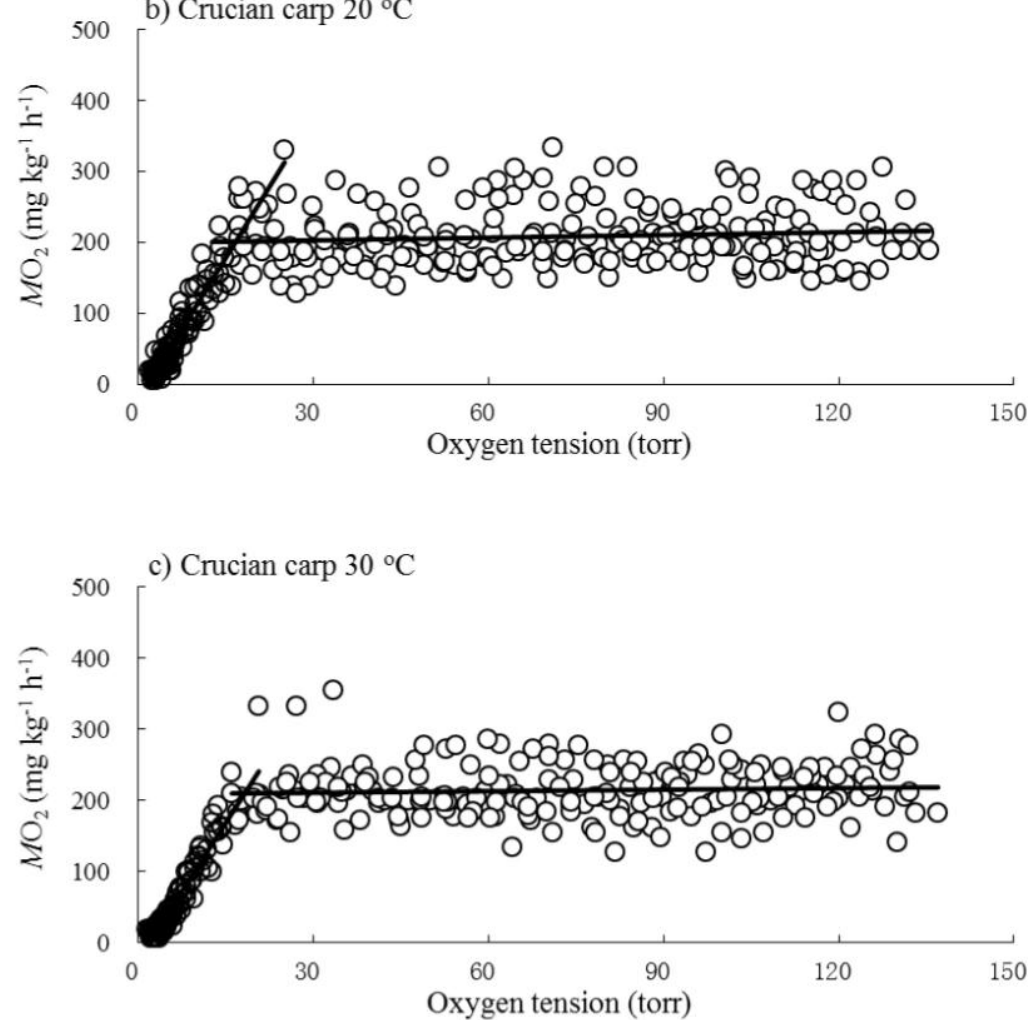

Figure 1a 


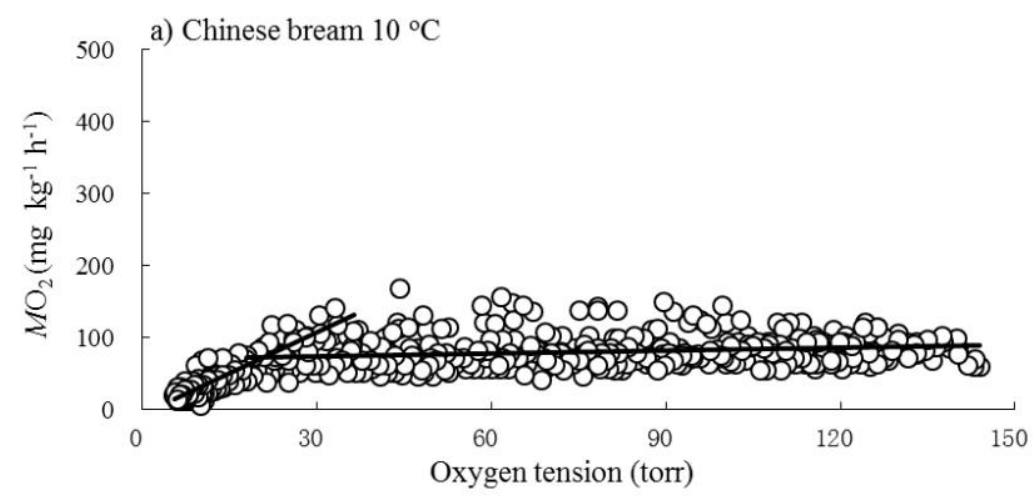

b) Chinese bream $20^{\circ} \mathrm{C}$
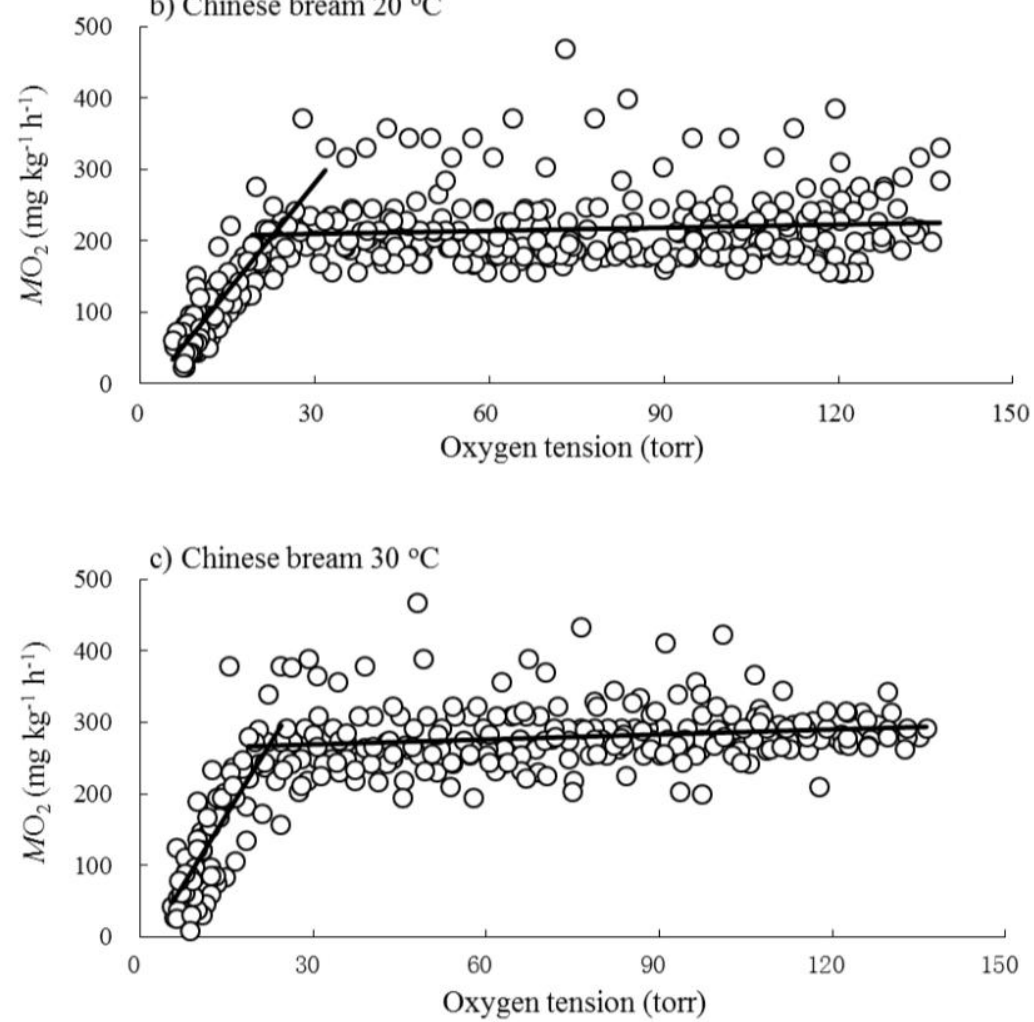

Figure 1b 

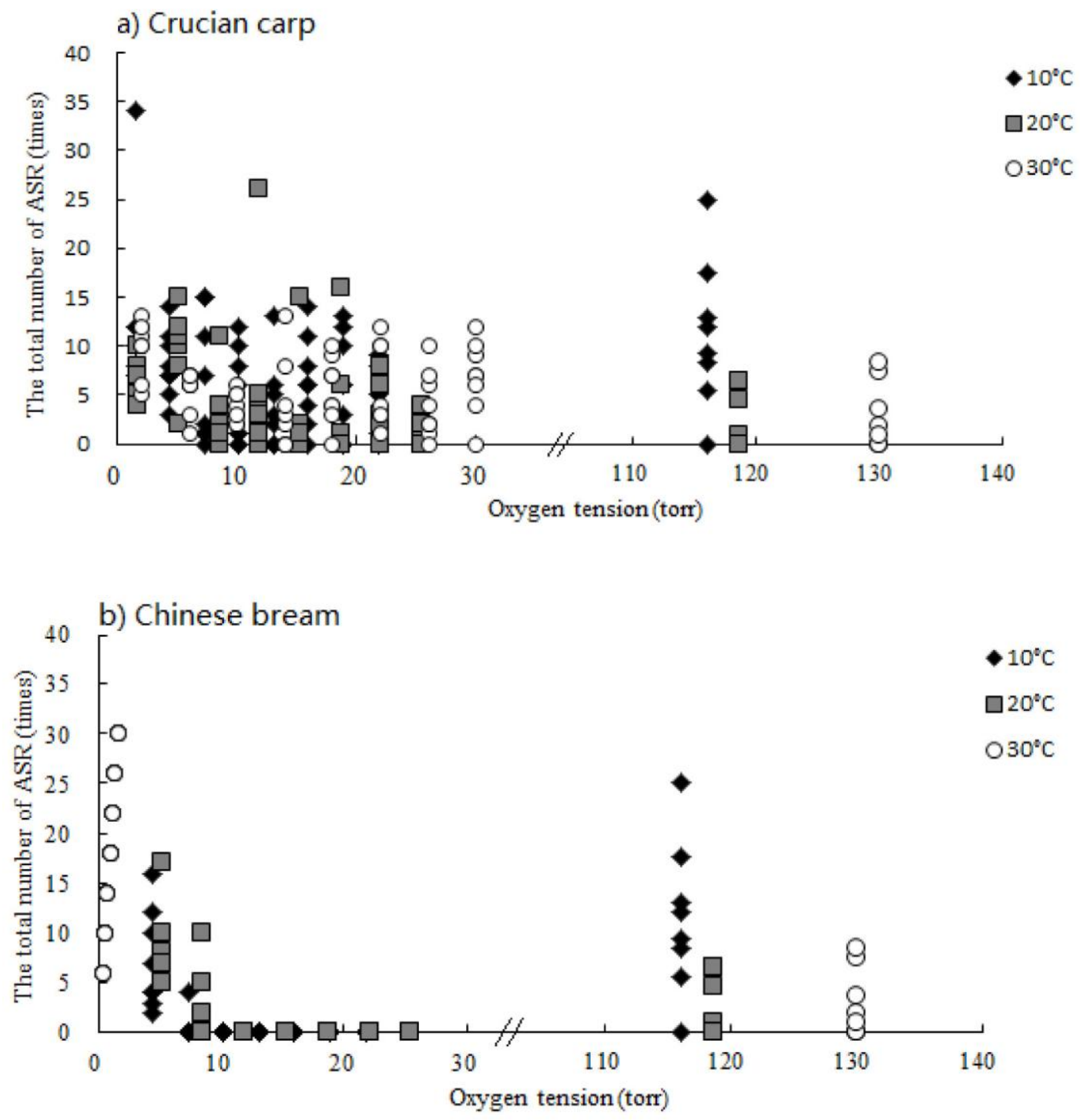

Figure 2 


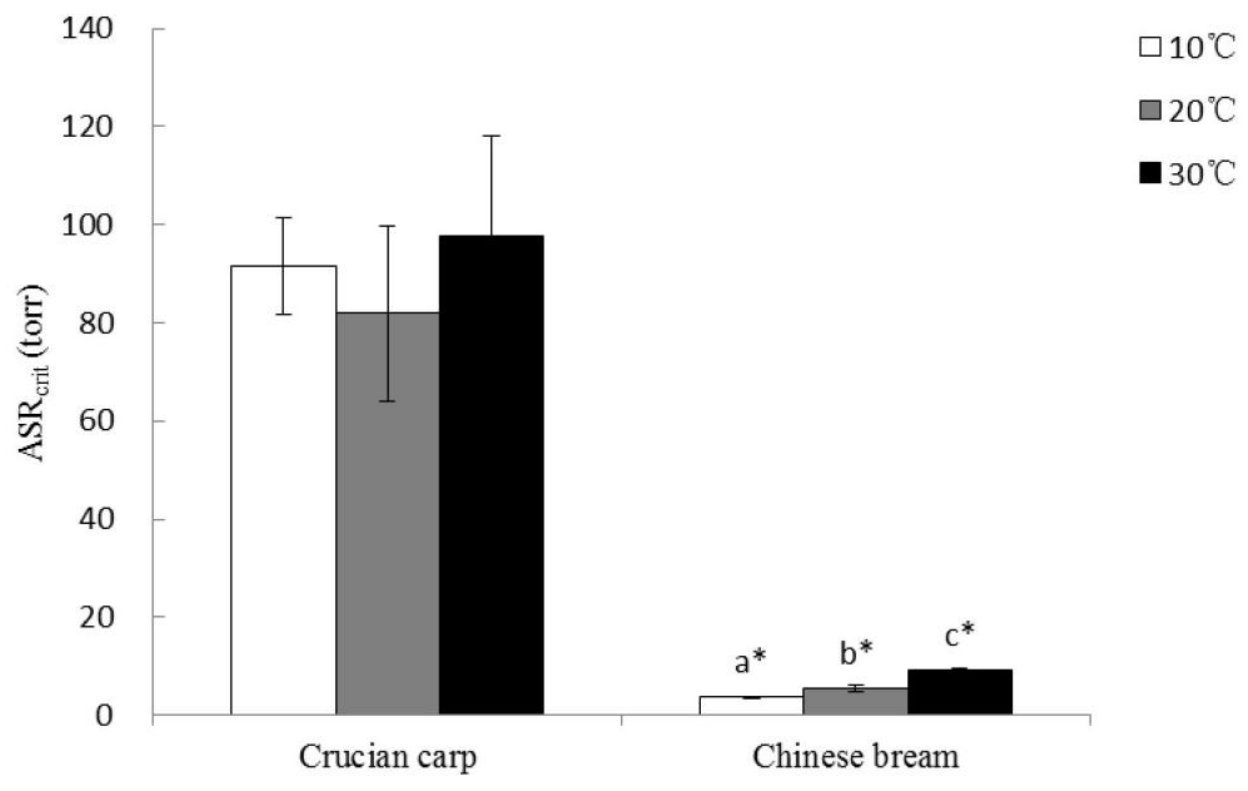

Figure 3 

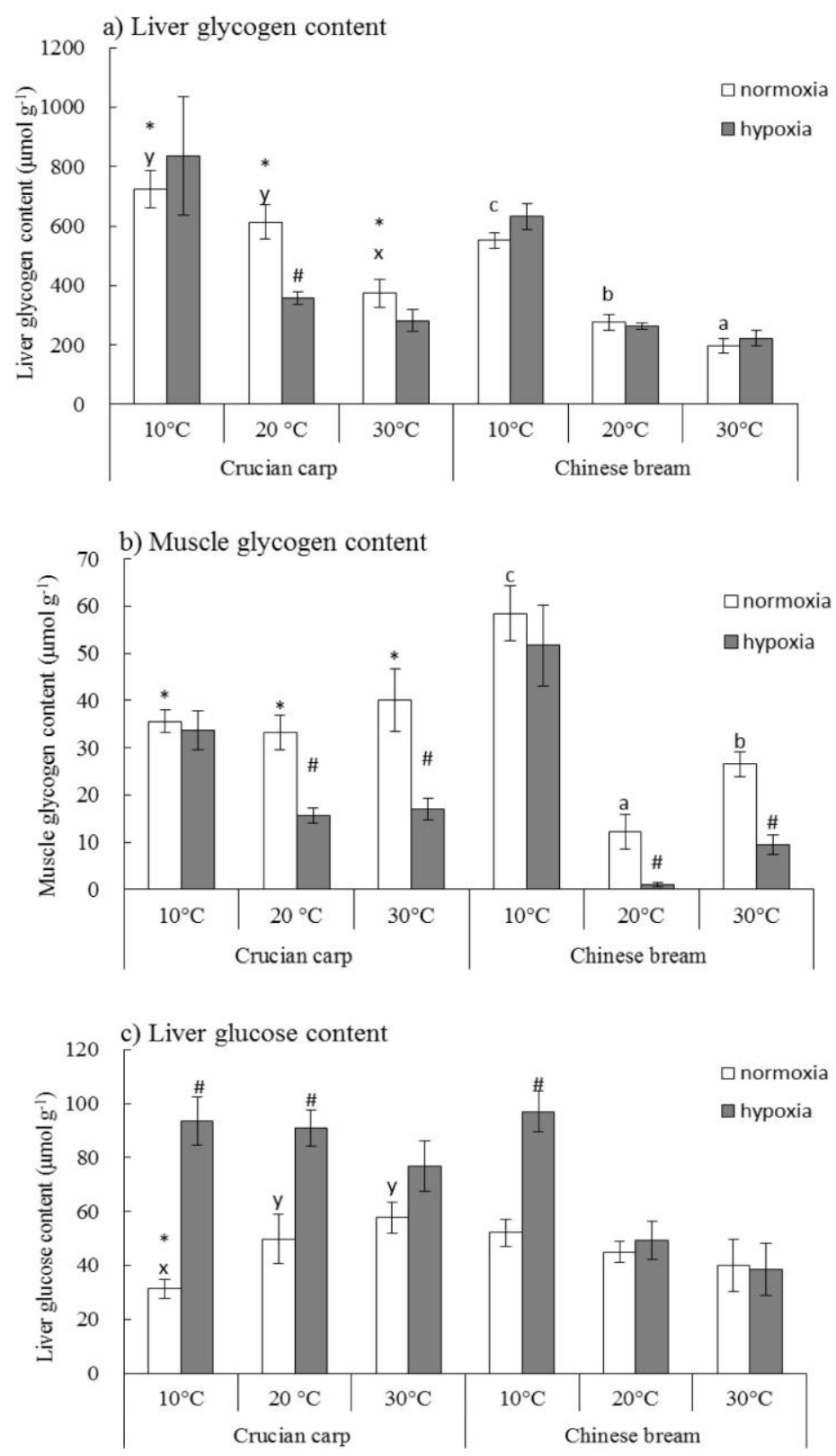

\section{Figure 4a-c}



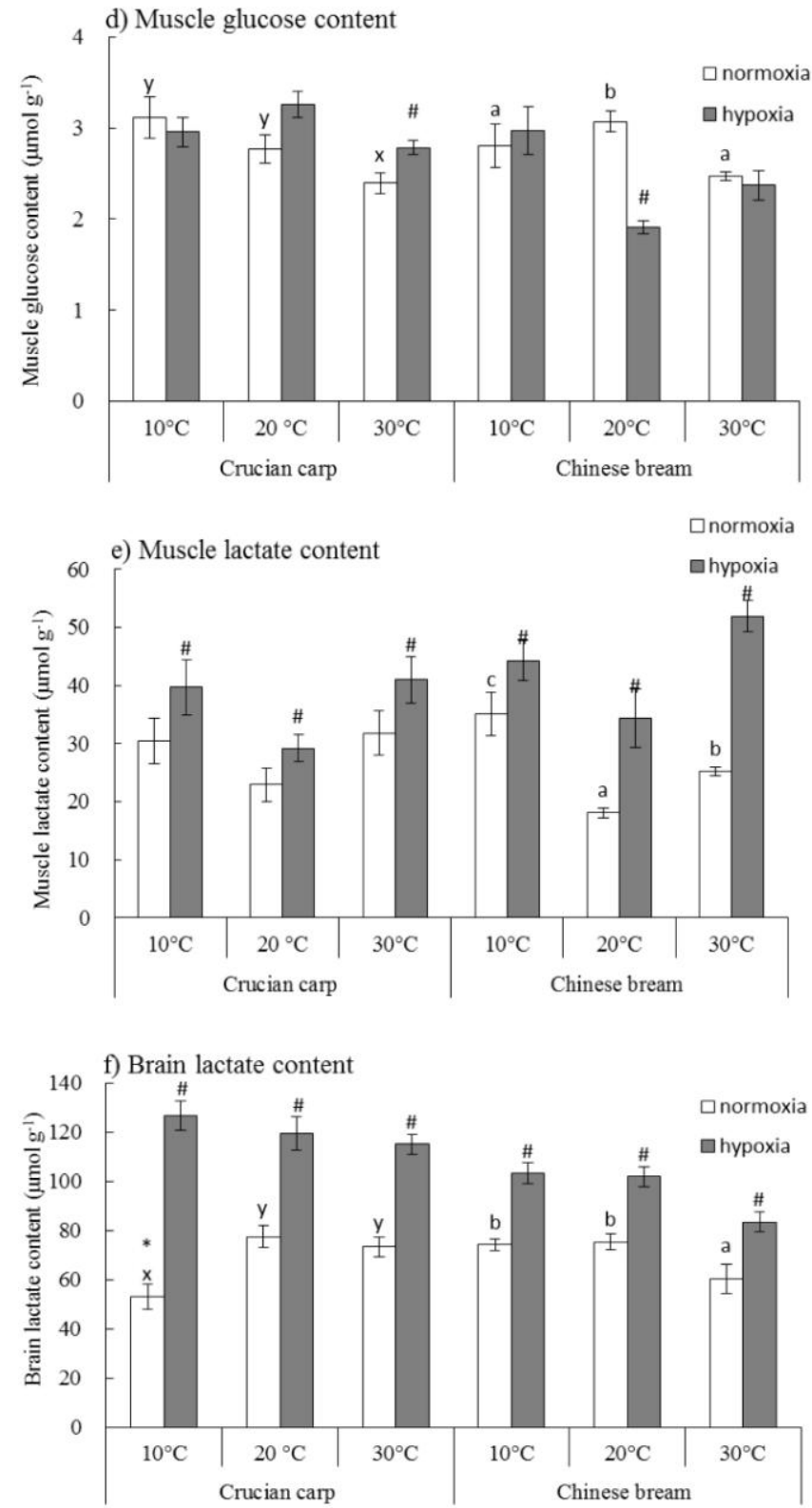

\section{Figure 4d-f}



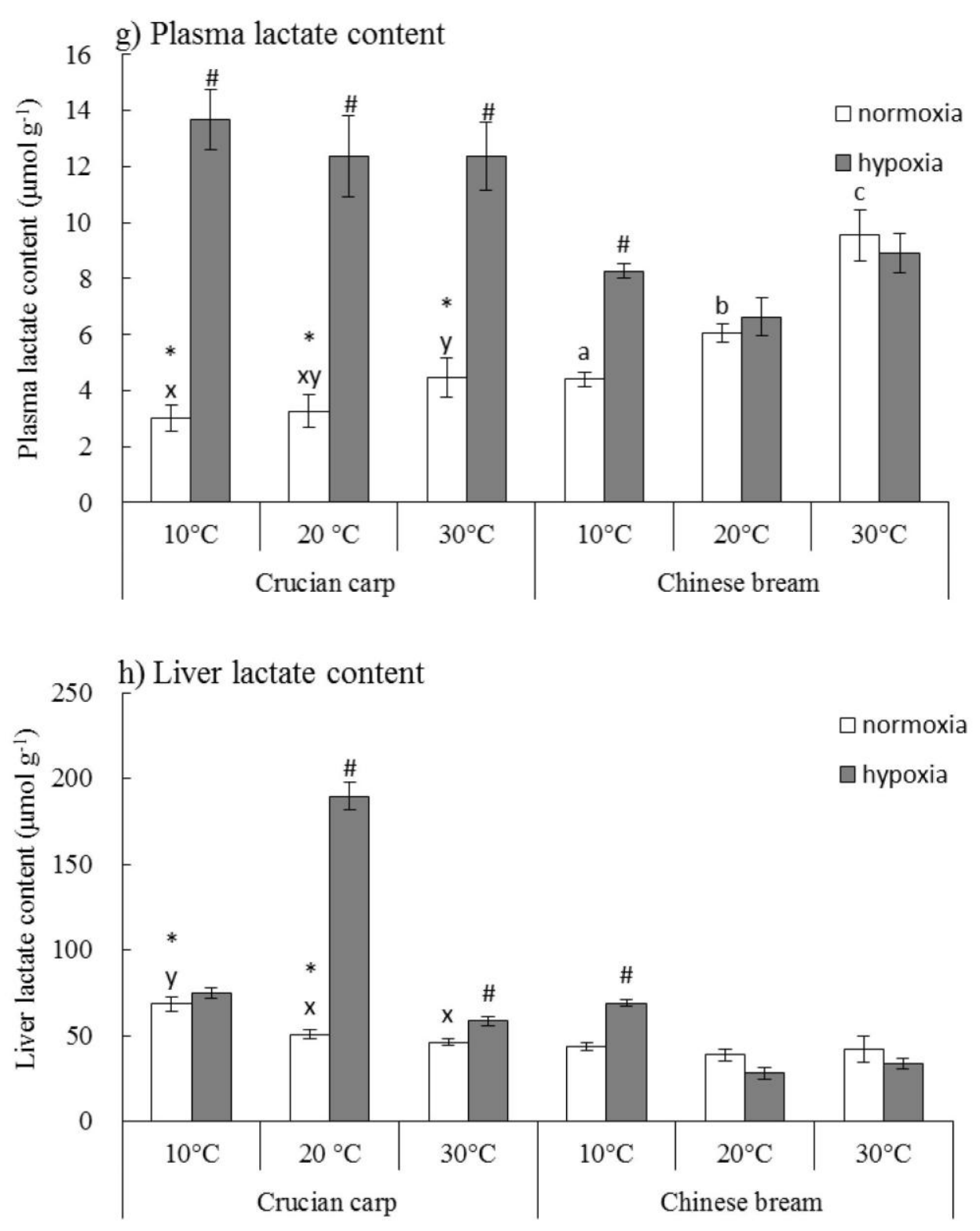

Figure 4g-h 